\title{
Gene self-control: when pre-mRNA splicing variants become competing endogenous RNAs
}

\section{Zhi-xiang Lu* \\ Department of Microbiology, Immunology, and Molecular Genetics, University of California Los Angeles, Los Angeles, CA, USA}

${ }^{*}$ Correspondence: zhixianglu@ucla.edu

Edited by:

Fengfeng Zhou, Shenzhen Institutes of Advanced Technology, China

Reviewed by:

Jie Wu, Massachusetts Institute of Technology, USA

Keywords: alternative splicing, nonsense-mediated decay, competing endogenous RNAs, non-coding RNAs, CDKAL1

\section{A commentary on}

Identification of a splicing variant that regulates type 2 diabetes risk factor CDKAL1 level by a coding-independent mechanism in human

by Zhou, B., Wei, F. Y., Kanai, N., Fujimura, A., Kaitsuka, T., and Tomizawa, K. (2014). Hum. Mol. Genet. 23, 4639-4650. doi: $10.1093 / \mathrm{hmg} / \mathrm{ddu} 184$

Since Richard J. Roberts and Phillip A. Sharp discovered split genes (genes are interrupted by RNA-encoding regions called exons and non-coding segments called introns in eukaryotic genome) in 1970's, scientists have been finding many genes can generate more than one mRNA transcripts through AS (alternative splicing, e.g., by different exon-exon combination). This AS strategy increases protein repertoire, encodes proteins with diverse and sometimes even antagonistic activities (Kelemen et al., 2013). A new study led by Dr. Kazuhito Tomizawa and first author Bo Zhou from Kumamoto University in Japan reports that CDKAL1-v1 (Cdk5 Regulator Subunit Associated Protein 1-Like), one splicing variant of CDKAL1, has no coding ability but acts as a miRNA sponge RNA, which regulates its full-length CDKAL1 protein (Zhou et al., 2014). Their results give us a unique paradigm of how AS possesses a regulatory role in controlling gene expression.

In addition to functioning as an "internal paralog" to deliver protein-coding message (Modrek and Lee, 2003), the main well-known mechanism of gene regulation by AS is alternative splicingcoupled nonsense-mediated decay (ASNMD). Briefly, Pre-mRNA alternative splicing creates unstable mRNA isoforms with PTC (premature termination codon). Generally, if a PTC site is more than $\sim 50$ nucleotides upstream of the last exon-exon junction, this RNA isoform will be degraded by NMD, an RNA surveillance pathway to clean up splicing errors which may lead to damaging truncated proteins (Sibley, 2014). For example, PTBP1 (polypyrimidine tract-binding protein 1) is one typical splicing regulator; it can regulate its own gene level through PTBP1-dependent exon 11 skipping to generate an AS-NMD transcript (Wollerton et al., 2004). The auto regulation through this negative-feedback loop fine-tunes PTBP1 protein level in normal development (Figure 1A). Zhou et al.'s study reveals a new mechanism where AS can regulate its own gene via competition for common miRNAs. Like regulation of PTEN functional protein by crosstalk from both pseudogene PTENP1, and cognate genes by competing for common miRNAs of tumor suppressor PTEN (Poliseno et al., 2010; Tay et al., 2011), AS offers a simpler way to generate ceRNAs (competing endogenous RNAs) by indirectly regulating its own gene in this codingindependent manner. Zhou et al. find that although CDKAL1-v1 is a short splicing variant which contains a PTC, it is not subjected to NMD. Interestingly, this non-coding RNA has the same targeting

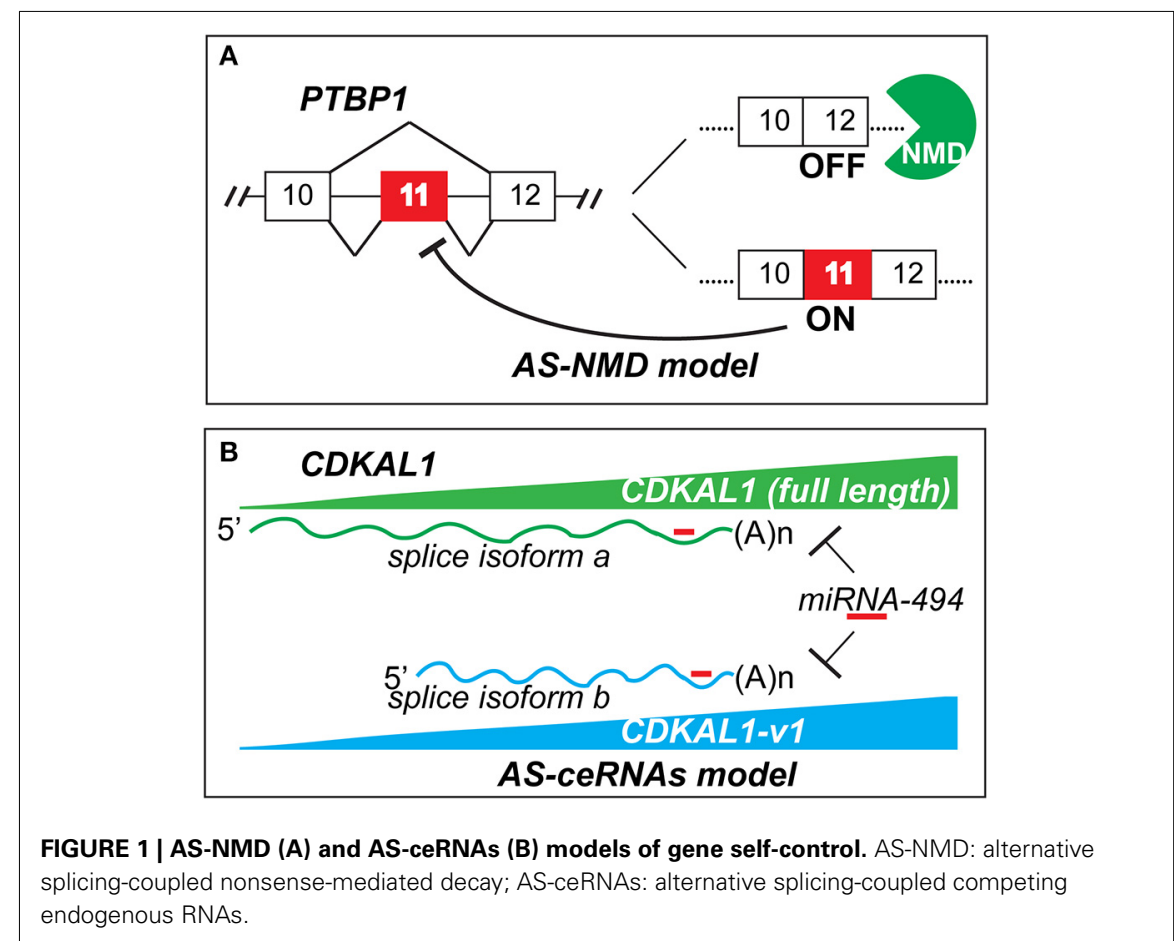


miRNA as full length CDKAL1, of which is a type 2 diabetes risk factor associated with insulin secretion. By competing miRNA bindings, CDKAL1-v1 RNA level displays concordant expression pattern with the full length CDKAL1 mRNA and protein levels (Figure 1B). Small interfering RNAs knockdown of CDKAL1-v1 markedly reduces the full CDKAL1 level or vice versa. Their data suggest CDKAL1-v1mediated $C D K A L 1$ gene may underlie type 2 diabetes pathogenesis. Here I term such AS regulatory mechanism as alternative splicing-coupled competing endogenous RNAs (AS-ceRNAs) (Figure 1B).

CDKAL-v1 study by Zhou et al. (2014) opens an intriguing new possibility, and elucidates a critical but understudied layer of AS role in gene control. Recent estimate by next-generation RNA sequencing uncovers more than $90 \%$ multi-exon human genes undergoing alternative splicing (Pan et al., 2008; Wang et al., 2008), but to answer how many of splicing variants are functional, not results of "aberrant splicing" or "noisy splicing," is still challenging. Post-transcriptional regulation by AS-ceRNAs model will encourage us to reevaluate the regulatory role of those uncharacterized splicing transcripts in reciprocal interactions with their own or cognate genes. RNA isoforms acting as ceRNAs such as CDKAL1-v1 may become splicing correcting targets for therapeutic development.

\section{ACKNOWLEDGMENTS}

I would like to thank Collin J. Tokheim (Johns Hopkins University, Baltimore, $\mathrm{MD)}$ for improving the language of the manuscript.

\section{REFERENCES}

Kelemen, O., Convertini, P., Zhang, Z., Wen, Y., Shen, M., Falaleeva, M., et al. (2013). Function of alternative splicing. Gene 514, 1-30. doi: 10.1016/j.gene.2012.07.083

Modrek, B., and Lee, C. J. (2003). Alternative splicing in the human, mouse and rat genomes is associated with an increased frequency of exon creation and/or loss. Nat. Genet. 34, 177-180. doi: $10.1038 / \mathrm{ng} 1159$

Pan, Q., Shai, O., Lee, L. J., Frey, B. J., and Blencowe, B. J. (2008). Deep surveying of alternative splicing complexity in the human transcriptome by high-throughput sequencing. Nat. Genet. 40, 1413-1415. doi: 10.1038/ng.259

Poliseno, L., Salmena, L., Zhang, J., Carver, B., Haveman, W. J., and Pandolfi, P. P. (2010). A coding-independent function of gene and pseudogene mRNAs regulates tumour biology. Nature 465, 1033-1038. doi: 10.1038/nature09144

Sibley, C. R. (2014). Regulation of gene expression through production of unstable mRNA isoforms. Biochem. Soc. Trans. 42, 1196-1205. doi: 10.1042/BST20140102

Tay, Y., Kats, L., Salmena, L., Weiss, D., Tan, S. M., Ala, U., et al. (2011). Coding-independent regulation of the tumor suppressor PTEN by competing endogenous mRNAs. Cell 147, 344-357. doi: 10.1016/j.cell.2011.09.029
Wang, E. T., Sandberg, R., Luo, S., Khrebtukova, I., Zhang, L., Mayr, C., et al. (2008). Alternative isoform regulation in human tissue transcriptomes. Nature 456, 470-476. doi: 10.1038/nature07509

Wollerton, M. C., Gooding, C., Wagner, E. J., Garcia-Blanco, M. A., and Smith, C. W. (2004), Autoregulation of polypyrimidine tract binding protein by alternative splicing leading to nonsense-mediated decay. Mol. Cell 13, 91-100. doi: 10.1016/S1097-2765(03)00502-1

Zhou, B., Wei, F. Y., Kanai, N., Fujimura, A., Kaitsuka, T., and Tomizawa, K. (2014). Identification of a splicing variant that regulates type 2 diabetes risk factor CDKAL1 level by a coding-independent mechanism in human. Hum. Mol. Genet. 23, 4639-4650. doi: 10.1093/hmg/ddu184

Conflict of Interest Statement: The author declares that the research was conducted in the absence of any commercial or financial relationships that could be construed as a potential conflict of interest.

Received: 02 October 2014; accepted: 02 November 2014; published online: 19 November 2014.

Citation: $L u Z$ (2014) Gene self-control: when pre$m R N A$ splicing variants become competing endogenous RNAs. Front. Genet. 5:405. doi: 10.3389/fgene. 2014.00405

This article was submitted to Bioinformatics and Computational Biology, a section of the journal Frontiers in Genetics.

Copyright (c) $2014 \mathrm{Lu}$. This is an open-access article distributed under the terms of the Creative Commons Attribution License (CC BY). The use, distribution or reproduction in other forums is permitted, provided the original author(s) or licensor are credited and that the original publication in this journal is cited, in accordance with accepted academic practice. No use, distribution or reproduction is permitted which does not comply with these terms. 